\title{
Value Engineering applicability in design of sustainable, energy efficient buildings
}

\author{
Krystyna Araszkiewicz ${ }^{1, *}$ \\ ${ }^{1}$ The West Pomeranian University of Technology in Szczecin, Faculty of Civil and Environmental Engineering
}

\begin{abstract}
Value Engineering is an analytical method used to optimize costs, consisting of negotiations, searching for substitutes and more efficient use of raw materials. It can be an effective support in defining material solutions while designing energy-efficient buildings. The research method adopted in this article is an analysis of the literature on value engineering and on the added value of the construction project and analysis of empirical data concerning an exemplary design solution for external walls in a multi-family building. It has been assumed that the reduction of the projected costs of the construction project (elimination of resources which do not create added value for the client) and at the same time increasing the energy efficiency of the facility are possible under the conditions of applying value engineering. The result of the calculations is the reduction of project costs according to the proposed model of value engineering.
\end{abstract}

\section{Introduction}

In many industries, e.g. aerospace, automotive, mechanical, computer, etc. value management is an important part of the process of controlling production costs [1]. In the construction industry, however, it is observed that few design offices or contractors apply techniques that allow for optimisation of investment implementation costs while maintaining the requirements imposed by the client. Recently, this situation has begun to change. This is mainly due to the rising prices of construction materials and the lack of qualified staff, which means that contractors more and more often look for ways to carry out the order entrusted to them with the least possible effort and financial resources.

One of the methods to optimise cost and time is Value Engineering (VE). This is a well-known and widely used process of managing production costs in many areas of industry. This technique identifies all possibilities of reducing unnecessary expenses and other factors that do not meet or exceed the investor's expectations while ensuring an appropriate level of quality, reliability and functionality [1]. What is worth emphasising, value engineering differs from standard cost reduction methods based on the use of cheaper materials or resignation from certain product functions. Such a procedure leads to a reduction of expenses necessary for the implementation of the project, but usually at the cost of quality and reliability. VE is a thorough analysis of the design of a given facility, especially in terms of its economic and scheduling optimization [2]. Currently, the improvement of project value according to VE assumptions is often based on [3]:
- design simplifications to speed up and facilitate many works,

- standardisation of individual works resulting in an improvement in work efficiency through the repetition of activities and a smaller number of errors made by workers during construction,

- unification of construction technology, which will increase the efficiency of the works carried out,

- prefabrication of structural elements which allows to save a lot of work,

- an analysis of the availability of the building materials in question in the vicinity of the project site to avoid a situation where the supply of the necessary products would have to be transported from places far away from the project site.

In addition to the concept of value engineering, terms such as Value Management (VM) or Value Analysis (VA) are also used. Although these terms sound very similar and are often used as synonyms, the literature indicates differences in the definition of these terms. According to the available publications, Value Management is the broadest issue that has three components, namely [4]:

- Value Planning, which is used to shape the project concept,

- Value Engineering in question covering only the design and implementation phase of the investment,

- Value Control applied at any stage of the project's life cycle, the aim of which is to monitor the effectiveness of Value Management.

The greatest potential for significant savings associated with the implementation of the intended construction project occurs in the first phase of investment preparation, i.e. during the development of the facility concept [4].

* Corresponding author: Krystyna.Araszkiewicz@ zut.edu.pl 
In the case of construction investments, savings from value engineering can be as high as 2 to $10 \%$. Bearing in mind contracts with amounts of several tens or hundreds of millions of Euro in mind, this allows for maintaining a significant amount of money in the budget, which can be allocated to other projects, without any loss of functionality or deterioration of the quality of the constructed object [5].

\subsection{Value engineering method}

The analysis and selection of optimisation solutions is divided into eight basic stages [6]:

- the phase of orientation,

- information phase,

- function analysis phase,

- the creative phase,

- the evaluation phase,

- development phase,

- the presentation phase,

- implementation phase.

The orientation phase is carried out in order to prepare for the analysis of the value of the project. It provides a basis for efficient and productive action by developing a problem description, collecting the necessary data, organising an analytical team and making a preliminary estimate of the amount of necessary financial resources for the project. The first step of this stage is to recognize and evaluate the function of the analysed object, thanks to which the value engineers will have the greatest chance to eliminate unnecessary costs of its production [5].

\subsubsection{Analysis of functions}

One of the most important stages of the entire production or service analysis is the function analysis phase. The concept of a function in terms of VE is defined as an action that achieves a set goal. It is a feature of a product that creates its usable value and determines the satisfaction of the needs of the investor or future customer. Each construction object fulfils many tasks performed by its individual elements. The essence of this stage is to separate the basic functions, without which the implementation of the investment does not make sense. Then the subfunctions should be defined [4]. It often happens that they are completely unnecessary, and their presence usually only causes an increase in construction costs. It is the elimination of such undesirable factors that do not meet or exceed the investor's expectations that results in a rational reduction of financial outlays needed to implement the project.

\subsubsection{Creation of optional solutions and assessment phase}

The main objective of the creative phase is to develop as many ideas as possible for an alternative solution for each function of the facility selected in the previous phase for further analysis. There are two methods of approaching a given issue: analytical and creative. The analytical approach is characterised by a team-based, gradual preparation of only one possible and most optimal option to develop the problem. The creative technique is a process of creating completely new concepts of solutions to a given problem, where each of the presented ideas will be an appropriate, satisfactory and working solution. Out of all the concepts created, the best action plan should be selected, based primarily on its implementation costs. The combination of knowledge and experience of the members of the research team will surely allow to obtain many beneficial ideas. At this stage of the analysis it is important to generate a free flow of ideas and concepts between the participants. Creative problem-solving techniques are the basis for effective value engineering [6].

The assessment phase is the stage at which concrete solutions are pre-selected. All concepts that do not meet the key requirements of the investor or future user should also be eliminated. A useful tool for this is to divide them into the following three categories [6]:

- realistic concepts, that is to say, concepts that are certainly achievable and their further development will achieve the desired goal,

- doubtful concepts that have great potential but require clarification or improvement of details,

- ineffective concepts with a low probability of success.

After selecting the solutions which, according to the research team, are most likely to improve the value of the project, they should be evaluated. Useful factors in this analysis are costs, impact on the schedule, level of complexity of a given solution or the size of its potential benefits.

\subsubsection{Development and implementation phase}

The development phase is the phase where the issues identified in the previous step are elaborated in detail in order to analyse the functionality, quality and cost calculation, which should cover the whole life cycle of the facility. All technical and organisational constraints should also be identified. This is the most important phase in value engineering as during this phase the research team, in consultation with the client, selects the best solution. The results of the analysis are formulated in the next stage - the presentation phase, during which the results of the conducted optimisation are presented to the investor [1].

The final stage is implementation. The VE team should then prepare the design documentation and technical specifications, which they will then pass on to their client. The impact of the introduced changes on the total costs of building the facility is also determined. It is worth emphasising that in order to achieve the greatest possible benefits from the performed analysis, the progress of subsequent works should be continuously monitored if possible [6]. 


\subsection{Use of VE for the analysis of solutions to reduce the energy consumption of a building}

The increasing interest in environmental protection and the assessment of the impact of construction projects on the environment over the last few decades has significantly affected the entire construction industry. The ever-increasing heat and humidity requirements placed on new buildings have forced investors to look for the best possible technological and material solutions, thanks to which the requirements will be met with the lowest possible increase in construction costs. This approach obviously applies to commercial investments aimed at generating the greatest possible profit for the investor. In other projects, the introduction of appropriate building partition solutions will allow for a significant reduction in operating costs, which will change the distribution of costs on a global scale throughout the entire life cycle of the facility. After a certain period of exploitation, the investment will start to generate profits, despite increased expenditure at the stage of implementation. Regardless of the investor's goal, the relationship between the building and the environment is an extremely important subject, especially in the era of constantly increasing tightening of the new buildings.

Continuous development of technology and environmental problems resulting directly from the acquisition of energy have a significant impact on changes in the heat and humidity requirements for newly constructed buildings. The interest in the problem is so important that neutral and even plus-energy buildings have already been designed. There is no doubt that the "buildings of the future" will be subject to everincreasing demands until complete environmental neutrality of the construction processes is achieved, so it is extremely important to follow developments in this area from an engineering point of view. It is worth bearing in mind that the benefits of this development also apply to future users, due to significantly lower operating costs [7].

\section{Figures and tables}

The analysis was carried out using a three-storey multifamily building with a total development area of 1242.00 $\mathrm{m}^{2}$ and a height of $12.30 \mathrm{~m}$ to the ridge as an example.

The original design was modified to increase energy efficiency during the building's operation.

\subsection{Solutions to increase the energy efficiency of the building}

One of the elements analysed was the construction of external walls. Three options were adopted. The following arrangement of material layers was adopted for individual variants:

- Variant 1 - silicate class 20 - thickness $24 \mathrm{~cm}$, coefficient $\lambda=0.44 \mathrm{~W} / \mathrm{mK}$; polystyrene class $15 \mathrm{~cm}$, coefficient $\lambda=0.038 \mathrm{~W} / \mathrm{mK}$
- Variant 2 - cellular concrete - thickness $24 \mathrm{~cm}$, coefficient $\lambda=0.11 \mathrm{~W} / \mathrm{mK}$; polystyrene - thickness $15 \mathrm{~cm}$, coefficient $\lambda=0.033 \mathrm{~W} / \mathrm{mK}$

- Variant 3 - silicate class $20-24 \mathrm{~cm}$ thick, coefficient $\lambda=0.44 \mathrm{~W} / \mathrm{mK}$; polystyrene $-15 \mathrm{~cm}$ thick, coefficient $\lambda=0.033 \mathrm{~W} / \mathrm{mK}$; cellular concrete $-12 \mathrm{~cm}$ thick, coefficient $\lambda=0.12 \mathrm{~W} / \mathrm{mK}$

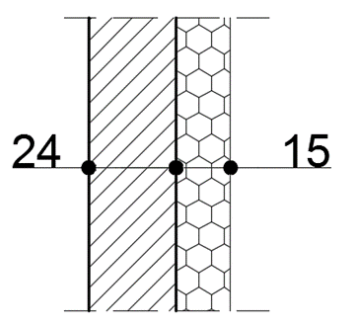

Fig. 1. Layer arrangement of external wall layers - Variant 1 and Variant 2 (maintaining the arrangement of partition layers when changing materials and maintaining strength parameters).

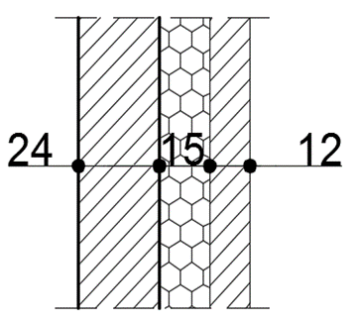

Fig. 2. Layer arrangement of the outer wall - Variant 3.

The thermal parameters for each variant have been calculated, including the thermal resistance of the partition and the heat transfer coefficient for the partition (Table 1)

Table 1. Results of thermal parameters calculation of the partition.

\begin{tabular}{|c|c|c|}
\hline Option & $\begin{array}{c}\text { Thermal resistance } \\
{\left[\mathbf{m}^{\wedge} \mathbf{2} \text { K/W] }\right.}\end{array}$ & $\begin{array}{c}\text { Heat transfer coefficient } \\
{\left[\mathbf{W} / \mathbf{m}^{\wedge} \mathbf{2} \text { K] }\right.}\end{array}$ \\
\hline 1 & 4.663 & 0.214 \\
\hline 2 & 6.897 & 0.145 \\
\hline 3 & 6.261 & 0.160 \\
\hline
\end{tabular}

The change of the brickwork element to cellular concrete in Variant 2 allowed for a significant reduction of the heat transfer coefficient for the partition. This solution ensures high thermal resistance of the partition, however, the silicate elements are characterized by a higher thermal capacity, which has a positive impact on the temperature stability of the room.

Modification according to variant 3 allows to maintain high thermal capacity of the load-bearing element and ensures high thermal resistance of the partition close to passive house standards. However, the partition scheme requires the external foundation walls to be extended and additional load on the foundation benches from the curtain wall to be considered.

\subsection{Costs and lead time}

Calculation of the cost of the external partitions for the example under examination was carried out, optionally. 
The basic variant is related to the scope of work involving the execution of a brick supporting structure and the execution of a foamed polystyrene thermal insulation layer. It was valued at PLN 403,314.82. In the case of retaining the layout of layers, but with a change of material (Option 2), the costs of works increased by PLN 46,589.54, but there was no difference in the time of the works. Option 3 involved a larger scope of works, including the need to extend the foundation wall from 24 to $51 \mathrm{~cm}$. It was assumed that the foundation benches would transfer additional load from the curtain wall in the form of $\sim 9.4 \mathrm{kN} / \mathrm{mb}$ of the bench, however, in reality, the determined load should be taken into account when checking the border states of the SGN and SGU.

It was also assumed that the expansion of the foundation wall requires the expansion of its structural reinforcement, the width of the stirrups has changed from $15 \mathrm{~cm}$ to $42 \mathrm{~cm}$, so that their total length has increased by $84 \mathrm{~cm}$, with a total number of stirrups equal to 2350 and a unit weight of this type of steel 0.617 $\mathrm{kg} / \mathrm{m}$, this gives an additional $\sim 1218 \mathrm{~kg}$ of steel. The total direct cost of making a three-layer external wall in the given parameters was calculated at about 435,260.47 PLN.

\section{Conclusions}

Calculations were made in order to provide data for the assessment of design solutions, taking into account both the planned function of the elements of the structure of the examined object and the costs of implementation of a given solution. Similar calculations have been carried out for variant solutions for the layout of floor layers on the ground, a variant analysis of the window installation technology has also been conducted.

The example mentioned in the article is only one of the possibilities when it comes to the selection of design solutions which have a positive impact on the thermal and humidity parameters of buildings. In order to illustrate the comprehensive application of Value Engineering, it would be necessary to analyse all potential elements that could be subject to optimisation of the energy efficiency parameters, while at the same time performing a cost and time analysis. The results showed that despite the need to introduce an additional scope of work on extending the external foundation walls, the introduction of an additional layer is more advantageous than other solutions, taking into account both the effect related to energy efficiency and the cost reduction effect. For the sake of completeness, an analysis of the full life cycle of the building should be carried out, taking into account changes resulting from optional material and technological solutions, then the result related to energy consumption (for heating the facility) and operating costs would be added to the set of decision criteria.

\section{References}

1. A. Dell'Isola, Value Engineering Practical Applications for design, construction, maintenance and operations, RS Means, Kingston (1997)

2. F. Usman, N.A. Jalaluddin \& S.A. Hamim, Value Engineering in building information modelling for cost optimization of renovation works: A case study. International Journal of Engineering and Technology (UAE), 7(4), (2018)

3. R. Cooper, Target costing and value engineering. Routledge, (2017)

4. A. Leśniak, K. Zima, Value Management of Construction Projects in Polish Conditions, Cracow University of Technology Publishing House, Cracow, (2010)

5. J. Brown, Value Engineering, Industrial Press Inc., New York (1992)

6. J. Mandelbaum, D. Reed, Value Engineering Handbook, Institute for defence analyses, Alexandria (2007)

7. A. E. Oke \& C.O. Aigbavboa, Sustainable value management for construction projects, Switzerland: Springer (2017). 